\title{
A grande angular em Mario de Andrade, a objetiva de Ramos: uma observação dos contos "O ladrão", de Mário de Andrade, e "Um ladrão", de Graciliano Ramos
}

\author{
Maria Luzia Carvalho de Barros ${ }^{1}$
}

RESUMO: Com o objetivo de exemplificar a distinção entre os olhares do chamado Movimento Modernista e do Romance de Trinta, este trabalho elege os contos "O ladrão", de Mário de Andrade e "Um ladrão", de Graciliano Ramos a fim de ilustrar os distintos tratamentos dados a um mesmo momento histórico e matéria social.

SUBSTRACT: This work aims to exemplify distinction between Brazilian Modern Movement and Neorealism in literature, choosing Mario de Andrade's "O ladrão" (The thief) and Graciliano Ramos' "Um ladrão" (A thief) short stories, in order to illustrate different approaches given to same historical and social moment.

PALAVRAS-CHAVES: Contos do século XX;Marginalidade; Sociedade KEYWORDS: Short stories; 20th century, marginality; Society

Sem dúvida, o capital não tem pátria, $e$ é esta uma de suas vantagens universais que ofazem tão ativo e irradiante. Mas o trabalho que ele explora tem mãe, tem pai, tem mulher e filhos, tem lingua e costumes, tem música e religião. Tem uma fisionomia humana que dura enquanto pode. E como pode, já que a sua situação de raiz é sempre a de falta e dependência. (Alfredo Bosi²)

\footnotetext{
1 Mestranda em Estudos Comparados pela Universidade de São Paulo, com o projeto "O Exílio: De punição individual à utopia coletiva"-A tematização da carência e da fuga na obra de Manuel Lopes e Graciliano Ramos. Projeto financiado pela CAPES. Contato: luuzeabarros@hotmail.com

2 BOSI, Alfredo. Céu, Inferno: ensaios de crítica literária e ideológica. São Paulo: Duas Cidades, 2003, p.19.
} 
São muitas as discussões acerca da relação de continuidade ou ruptura entre o Movimento Modernista e o Romance de Trinta. Os debates encampam desde a estrutura formal adotada por cada momento literário até o tratamento dado à realidade social brasileira nas obras que os representam. Acreditamos que a comparação que aqui iremos propor, entre duas ficções que representem cada momento, pode exemplificar o teor desses debates. As ficções são os contos "O ladrão", de Mário de Andrade, e "Um ladrão", de Graciliano Ramos.

O conto "O ladrão", de Mário de Andrade, faz parte do livro Contos novos, publicado postumamente, em 1947. O conto "Um ladrão", de Graciliano Ramos, faz parte de Insônia, também publicado em 1947. Ambos, entretanto, já haviam sido publicados em periódicos. O conto de Mário de Andrade é o desenvolvimento de uma crônica publicada no Diário Nacional, nos anos 30; já o de Ramos, tendo sido escrito em 1938, foi publicado no jornal A Tribuna, de Santos (SP), em 1939.

Trata-se de dois contos com escrita e publicação dentro de um mesmo período político-social brasileiro: o Estado Novo de Getúlio Vargas. As duas narrativas se passam em ambiente urbano, logo a similaridade do quadro social parece-nos evidente. O que vai alterar a realidade forjada nas ficções será, sobretudo, o olhar, ou, ainda, as perspectivas narrativas, como pontua Alfredo Bosi na epígrafe acima. Será a clareza com que se mostram as fisionomias dos individuos que vivem a realidade da falta e da dependência. A semelhança do título dos dois contos sugere uma proximidade temática; entretanto, algumas distinções fundamentais vão conduzir a análise aqui apresentada. Ela buscará demonstrar como, a partir da escolha da perspectiva narrativa, a abordagem dada ao tema do ladrão, ou ainda, do universo marginal, findará por apontar diferenças no tratamento dado à matéria social, podendo indicar ainda as propostas do Movimento Modernista, por um lado, e do Romance de Trinta, por outro.

Partindo de pressupostos teóricos do ensaio "A posição do narrador no romance contemporâneo", de Theodor Adorno, contido em Notas de literatura $I$, no qual o crítico alemão estabelece uma relação 
entre as perspectivas narrativas do começo do século $\mathrm{XX}$ com as câmeras cinematográficas, buscaremos traçar analogias entre esse argumento teórico e as vozes narrativas dos contos escolhidos. Assim, temos em Adorno:

(...) a nova perspectiva narrativa diminui a distância estética com o leitor: no romance tradicional, essa distância era fixa. Agora ela varia como as posições da câmara no cinema: o leitor é ora deixado do lado de fora, ora guiado pelo comentário até o palco, os bastidores e a casa de máquinas. (ADORNO, 2003; p.61)

A argumentação de Adorno, ao aproximar a voz narrativa da câmera de cinema, vai sugerir que as ficções terão no narrador o principal responsável pela seleção das cenas apresentadas ao leitor, assim como pela representação dos personagens e, principalmente, pelo universo social focalizado.

Então, para usar a definição de Adorno, as duas ficções aqui abordadas mostram movimentos de câmera bem distintos. Enquanto o autor modernista coloca seu tripé na rua, onde flagra quem passar por aquele trecho, o autor nordestino acompanha seu personagem muito de perto, como se o próprio personagem levasse a máquina em seu ombro, mesmo em se tratando de dois narradores em terceira pessoa.

\section{A grande angular de Mário de Andrade}

O conto "O ladrão", de Mário de Andrade, foi escrito em sua maturidade, passado já algum tempo da chamada fase heróica do modernismo. Algumas ambições, como a busca em fazer um retrato harmônico do cenário social brasileiro desta fase, porém, parecem persistir na produção do autor. Para Ivone Daré Rabello, a voz narrativa do conto "O ladrão" sugere a trucagem cinematográfica - de início o ângulo é superior, sua visão é dada de cima, para depois aproximar-se e, acrescente-se, finalmente fixar-se em um espaço, com pouca mobilidade. 
O conto é ambientado em uma vila da cidade de São Paulo, com destaque para uma rua habitada por imigrantes e/ou operários, mas também por pessoas da elite. Já daí vê-se a insistência do autor em diluir as diferenças sociais, pois todas as casas estão na mesma rua e no mesmo plano.

É nesta rua que serão construídas as tensões, ou a falta delas. O ladrão que intitula o conto será apenas uma sugestão, que, ao final da narrativa, terá sua existência posta em dúvida. Parece-nos que a escolha pela não-representação deste personagem, à margem do quadro social, a se julgar por sua nominação, pode ser uma maneira de ignorar a fração que estava totalmente marginalizada na sociedade brasileira de então; ou, ainda, de não inserir seus representantes no pólo da desordem que Antonio Candido nos propõe como um dos constituintes da formação dos paradigmas sociais brasileiros em seu ensaio "Dialética da malandragem" (CANDIDO, 2004).

O foco narrativo, contudo, prefere deixar a figura do ladrão ir, perdendo-a no horizonte. Ficam diante de sua lente, no mesmo espaço, a negra do cortiço, as operárias, a portuguesa rica, o padeiro e os que lhes seguem. Todos estes personagens estão, de alguma forma, inseridos no pólo da ordem e, juntamente com o guarda, irão lutar contra o risco da ação do contraventor. Temos aqui o Estado (representado pelo guarda) e a comunidade se unindo em razão de uma ameaça comum: o ladrão, cuja presença não se efetiva, mas vale como motivação para os moradores saírem à rua. Assim nos aponta Ivone Daré Rabello:

O enredo trama a formação do grupo que em aparência se constitui pela solidariedade. Este altruísmo é, no entanto, quase intransitivo, trata-se de ajudar não se sabe quem. Não importa o sujeito; importa proteger um território coletivo em nome da propriedade privada. (RABELLO, 1999; p.134)

A partir daí, o narrador começa a construir um momento festivo, de conciliação e harmonia no grupo de vizinhos; as moças vão à janela, 
um violinista toca uma canção, forma-se uma bolha no tempo que suspende as diferenças e permite aos moradores desfrutarem juntos aquele momento, da negra do cortiço à portuguesa rica. Assim, os distintos comungam na rua. As tensões de classe estão praticamente diluídas nesta cena festiva. Roberto Schwartz, a propósito da análise de "Pobre Animália", de Oswald de Andrade, faz observações acerca da proposta modernista que, acreditamos, aqui se exemplifica:

Para que o moderno-de-província, o moderníssimo e o arcaico se acomodem, é preciso que se encontrem. Os locais inventados por Oswald para a sua conciliação, espécies de praça pública, constituem achados em si mesmos. Pode ser o Brasil inteiro, dividido ao meio por um trem, como o vazio pelo meridiano (...) onde a boa gente brasileira, sem discriminação entre negros e brancos, mas com uma alfinetada nos mulatos, vence o pedantismo lusófono e põe o pronome no lugar errado o que é o certo. (SCHWARZ, 1987; p.24).

Não se pretende aqui discutir a dicção modernista, mas de exemplificar o artificio adotado para valorizar a realidade social brasileira de então, ou, para usar a linguagem cinematográfica, o uso exagerado da lente grande angular, que mostra tudo, já que aproxima muitas vezes o que está longe, mas com certo grau de deformidade e pouca nitidez.

Desta forma, o narrador, em Andrade, apenas tangencia a maioria dos personagens, que entram e saem de cena, sem que nada saibamos sobre suas condições de vida, dramas ou traços. A exceção é a portuguesa rica, em quem, por fim, a câmera dará um "zoom" (movimento em que a câmera se aproxima de um objeto que está longe), privilegiando a personagem. É a única representante da elite entre os moradores e seu retrato é simpático ao leitor; ela é bela, jovem, rica e generosa, apesar de ser desfrutável, segundo insinuações dos moradores. O narrador constrói um personagem sensivel, mas, na verdade, é nela que reside a contravenção - é ela quem vai transgredir o bom andamento da vida da "gente miúda" a qual Mário de Andrade pretende visitar no conto. Sua transgressão, todavia, é de cunho moral, 
pois a portuguesa é infiel ao marido, que, por sua vez, parece indiferente à mulher. Com isso, a traição da esposa parece ser justificável. A representação privilegiada desta mulher, que recebe padeiros em casa e médicos em início de carreira, sugere, a uma só vez, sua leviandade e generosidade:

Veio chegando, era a vergonha do quarteirão, a mulher do português das galinhas. Era uma rica, linda com aqueles beiços largos, enquanto o Fernandes quarentão lá partia no "Ford" passar três, quatro dias na granja de Santo André. Ela quem disse ir com ele! Chegava o entregador da "Noite", batia, entrava. Ela fazia questão de não ter criada, comia de pensão, tão rica! (ANDRADE, 1990; p.39)

O destaque dado a esta personagem parece remeter à nostalgia do período do início do modernismo, quando figuras da elite paulistana patrocinavam as artes e eram dadas a gestos libertários. De fato, a portuguesa em questão destoa das demais habitantes da rua; com sua chegada as demais mulheres, representantes da "gente miúda", tão querida de Mário de Andrade, ganham certo ar mesquinho, reforçando seu traço provinciano.

Com a presença da linda portuguesa, a gentileza dos homens para com ela e o despeito das demais, operárias honestas e senhoras casadas, dá-se a quebra da harmonia. A pulsão sexual, elemento da vida privada, vai à praça, e o moralismo da "gente miúda" vai fazer dissipar a festa da comunidade:

Foi um silêncio carregado, no grupo, assim que ela chegou. As duas operárias honestas se retiraram com fragor, facilitando os homens. Se espalhou um cheiro por todos, cheiro de cama quente, corpo ardente e perfumado recendente. (ANDRADE, 1990; p.36)

Desfeita a frágil harmonia, não pela classe social da portuguesa, mas por sua vida sexual reprovável, a festa acaba e todos se recolhem. Ficam ainda, ao longe, alguns operários esperando o bonde na rua debaixo, mas a câmera não se aproxima, mantida que fica no mesmo lugar. E, assim como o ladrão que passou sem ser visto, os operários 
encobertos pela noite servem com ponto de fuga para finalizar a narrativa.

\section{A objetiva de Ramos}

O conto de Graciliano Ramos, como já dito, tem um narrador muito próximo à personagem central. Em boa parte da obra a voz narrativa adquire tamanha aderência à perspectiva do personagem a ponto de sugerir que o próprio ladrão tem sobre seus ombros a câmara, como no Cinema Novo de Glauber Rocha.

Entretanto, no início da ficção, o narrador tem seu discurso destacado da voz da personagem, explicando ao leitor as técnicas necessárias para o bom desempenho da atividade de ladrão e alertando para o fato de que o personagem em questão não as possuía. No decorrer da leitura, a perspectiva do personagem e a do narrador se aproximam, havendo momentos em que elas chegam até a se confundir, como veremos mais adiante.

Este personagem está inserido na marginalidade e, como tal, vive na completa falta; é morador de rua e seu principal vínculo é com outro ladrão mais experiente, Gaúcho (também citado em Memórias do cárcere). Entretanto, em sua construção, o narrador deixa claro que o ladrão já frequentou a escola, portanto é um marginal letrado e carrega uma visão crítica incomum da sociedade, percepção atípica para um indivíduo da sua condição.

A residência que pretende assaltar fica no final de uma rua, no alto do morro, posição privilegiada, diferentemente da casa da portuguesa de Mário de Andrade, que se encontra junto à vila de operários, sobradinhos iguais, um ao lado do outro. Assim, a localização da residência no conto de Ramos, destacada das demais, pode sugerir a cisão nítida entre o mundo marginal e o mundo da elite.

Mas é dentro do ambiente privado que o narrador irá trazer ao leitor não apenas a tensão de classes, como também a visão crítica que o marginal possui da classe dominante. O retrato negativo da elite não 
precisa mais do que um "zoom" em apenas um membro da dona da casa:

(...) avistou um braço caído fora da cama. Braço de velha, braço de velha rica, de uma gordura nojenta. A mão era papuda e curta, anéis enfeitavam os dedos grossos. (RAMOS, 1985; p.28)

Acreditamos que este trecho pode demonstrar a proximidade entre a voz narrativa e o personagem, pois a visão do ladrão e a do narrador parecem se confundir: quem viu a mão? Quem a diz "nojenta", o narrador ou o ladrão?

O excerto acima sugere uma burguesia opulenta e fútil, dada a gordura da moradora, além do fato de esta dormir carregada de jóias, que não a enfeitam, pelo contrário, auxiliam na construção de uma imagem grotesca.

A voz narrativa também reforça a experiência da carência na vida do ladrão; além de dinheiro, falta-lhe todo o resto. Assim, todas suas necessidades vão irromper dentro da residência, a fome vai guiar seus passos:

Onde estaria o queijo que na antevéspera se achava em cima da geladeira? Procurou-o debalde. Entrou na cozinha, mexeu nas caçarolas, encontrou pedaços de carne, que devorou quase sem mastigar. (RAMOS, 1985; p.33)

Também encontra modos de demonstrar alguns valores do ladrão, como o respeito pelas imagens de santos dos moradores:

Abriu a porta de ferro, acendeu a lâmpada, viu um oratório. Desejou apoderar-se dos resplendores das imagens e do bordão de São José, de ouro, pesado. Afastou-se com medo da tentação. Não cometeria semelhante sacrilégio. (1985; p. 29)

Nesta passagem, podemos perceber os valores cristãos, que findam por reter seus atos; tais pudores religiosos talvez possam ser lidos como herança do Brasil arcaico, que divide a mente do ladrão com 
os novos valores, do capitalismo, visto que são esses últimos que compõem seu sonho de inserção social e motivam suas ações:

Um capital. Estabelecer-se-ia com um café no subúrbio, longe de Gaúcho e daqueles perigos. Café modesto, com rádio, os fregueses, pessoas de ordem, discutindo futebol. Ouviria as conversas sem tomar partido, não descontentaria ninguém e fiscalizaria os empregados rigorosamente. Um patrão, sim senhor... (1985; p. 32)

Note-se o salto que o personagem ambiciona - de marginal a patrão. Esta possivel mobilidade social, que pula etapas, nos parece similar à condição brasileira, passando de país agrário a industrializado, ou, ainda, conforme aponta Roberto Schwartz, de arcaico a moderno.

A pulsão sexual no conto também é responsável pela mudança de rumo da narrativa. O ladrão, que mesmo sem possuir a técnica necessária, já conseguia bons frutos em sua iniciativa, acaba por permanecer mais tempo e se arriscar em um beijo. O episódio já se pronunciava no início da narrativa, quando o narrador cita que há apenas um local iluminado na casa, trata-se de um quarto, onde dorme uma jovem nua, com a porta destrancada. A identidade da jovem não é revelada, pode ser filha dos donos da casa, empregada, visitante. Entretanto, chama a atenção que esta durma nua, com a luz acesa e porta destrancada. Sem nos estendermos, o fato é que para este ladrãozinho desprovido de tudo, este quarto funciona como uma armadilha e vai retê-lo na casa até sua prisão:

A principio foi um deslumbramento, a casa girando, a cama girando, ele também girando em torno da mulher, transformado em mosca. Girando, aproximando-se e afastando-se, mosca. E a necessidade de pousar, para se livrar dos giros vertiginosos. (1985; p. 35)

A oscilação do ânimo da personagem chega neste momento a seu grau mais baixo, e de possível patrão ele vai a inseto. Torna-se a mosca, como mosca vai à prisão. 
Como se pôde perceber nos trechos citados, o retrato do ladrão, que apesar de não ter nome, nem endereço, fica bastante nítido ao leitor, é dado graças à proximidade estabelecida entre a perspectiva narrativa e a do personagem, ficando claro ao leitor suas necessidades mais urgentes, bem como suas aspirações de futuro, muitas vezes umas opondo-se às outras. Cabe ainda lembrar que os gestos do personagem são pautados pela oscilação entre sucesso e fracasso. Ele vive a experiência da margem e da possibilidade de dar um salto sobre esta, tornando-se um capitalista:

$\mathrm{O}$ que o preocupava naquele momento, porém, era menos o receio de ser preso que a convicção da própria insuficiência, a certeza de que ia falhar. (RAMOS, 1985; p.28)

Esta oscilação talvez possa ser comparada à condição da nação brasileira no período, que tinha ambições de se inserir entre os países industrializados sendo um país periférico e carregando todos os traços desta condição.

\section{O voo, a mosca, o inseto}

Diante das observações acerca das duas obras literárias, é possível perceber no olhar do narrador não apenas a solução estética como também as estratégias discursivas para compor um retrato distinto de uma mesma matéria social.

Podemos perceber no conto "Um ladrão", de Graciliano Ramos, uma denúncia mais robusta, pautada em um cotidiano de exclusão e violência, sem sentimentalismos, o que nos parece corresponder melhor à vida das pessoas condenadas a viver nas franjas sociais do novo sistema que se implantava no Brasil da década de 30 do século XX. Conforme nos apontou Antonio Candido, a pré-consciência do atraso, do subdesenvolvimento e, sobretudo, a percepção de que as utopias progressistas, ligadas à entrada de nosso país no processo de industrialização não encontravam eco na realidade, apontavam para a perpetuação das injustiças sociais.

Já em "O ladrão", de Mário de Andrade, embora seja visível certo desencanto com o futuro, ainda persiste o traço de um bom convívio entre os distintos grupos sociais. Parece-nos, assim, que as utopias progressistas não estavam de todo extintas da produção literária do autor paulista. 
Assim, em Mário de Andrade, o ladrão passa como se voasse sobre a narrativa, tendo sua presença sentida, mas não sendo visto; em Graciliano Ramos, o ladrão se torna mosca que ao pousar é capturado.

\section{Referências bibliográficas}

ADORNO, Theodor. Notas de literatura I. Rio de Janeiro/ São Paulo: Duas Cidades, 2003.

ANDRADE, Mário. Contos novos. Belo Horizonte: Itatiaia, 1990.

BOSI, Alfredo. Céu, Inferno: ensaios de crítica literária e ideológica. São Paulo: Duas Cidades, 2003.

CANDIDO, Antonio. O discurso e a cidade. Rio de Janeiro/São Paulo: Duas Cidades, 2004.

RABELLO, Ivone Daré. A caminho do encontro: uma leitura de Contos novos. Cotia:Ateliê, 1999.

RAMOS, Graciliano. Insônia. Rio de Janeiro/São Paulo: Record, 1985. SCHWARZ, Roberto. Que horas são?ensaios. São Paulo: Companhia da Letras, 1987. 